\title{
Evaluation of Residual Stress by X-Ray Diffraction and Correlative Stress Modelling
}

\author{
Kumar, Sandeep ${ }^{1, a}$, Crivoi, Alexandru ${ }^{1, a}$, Tan, Ming Jen, ${ }^{2, \text { b, }}{ }^{*}$ Tai, Anna ${ }^{3, c}$, \\ Marinescu, Iulian ${ }^{3, c}$ \\ ${ }^{1}$ Rolls-Royce@NTU Corporate Lab., Singapore \\ ${ }^{2}$ Sch. of Mech. \& Aerospace Engg., Nanyang Technological University, Singapore \\ ${ }^{3}$ Rolls-Royce Singapore Pte. Ltd., Singapore \\ kumar.s@ntu.edu.sg a , acrivoi@ntu.edu.sg ${ }^{a}$, mjtan@ntu.edu.sg ${ }^{\text {b, }}$, \\ anna.tai@rolls-royce.com ${ }^{\mathrm{c}}$, Iulian.Marinescu2@rolls-royce.com ${ }^{\mathrm{c}}$
}

Keywords: Residual Stress, TIG Welding, X-Ray Diffraction, Numerical Simulation, Aerospace Material

\begin{abstract}
Residual stress is an unavoidable problem which occurs during any manufacturing process or during repair when it is unwanted or uncontrolled, and becomes a limitation to the service life of a component. Welding is one of the common repair methods used on gas turbine engine components that develops high residual stress, and uncontrolled residual stress may appear in several manufacturing processes which involves uneven distribution of heat, mainly in a localised manner (i.e. at the cutting/welding tip/zone). This study is mainly focused on the estimation of the surface residual stress after welding on aerospace material; here X-Ray diffraction (XRD) is used for analysis since it is an accurate NDT method used for measuring residual stress. X-ray diffraction is made a semi-destructive method by removing material using electropolishing to micron level for analysis of sub-surface stresses, as X-ray diffraction method has low penetration depth. Residual stress measurement is carried out at surface level and correlated with numerical simulation of residual stress due to welding.
\end{abstract}

\section{Introduction}

Most of the manufacturing and repair processes generate residual stresses in components. Residual stress is critical and needs to be controlled. In most cases, understanding the distribution versus the depth of the residual stress is of interest in various industries. To acquire this information, the most commonly used methods are X-ray diffraction with layer removal and central hole drilling [1]. Residual stresses in welded joints primarily develop due to differential weld thermal cycle (significantly varying temperature) experienced by the weld metal and region closed to fusion boundary i.e. heat affected zone. Type and magnitude of the residual stresses vary continuously during different stages of welding. The stresses in the weld joints develop due to typical nature of welding process i.e. localized heating and cooling leading to varying volumetric expansion and contraction of metal around the weld zone (Fig. 1 (a),(b),(c)) [2].

The objective of this paper is to measure the residual stress development at surface level to understand the significant impact on the performance of the component in aerospace materials. X-ray diffraction with layer removal can be used for the measurement of residual stress in the sub-surface level which will help to understand others problems e.g. failure. The results obtained from the semidestructive method at surface level will be correlated with stress modelling and also used to comprehend the residual stress distribution [3]. Finite element model of the specimen is developed, and the welding simulation is performed to model the resulting stress fields.

\section{Experimental methods}

(c) (1) Content from this work may be used under the terms of the Creative Commons Attribution 3.0 license. Any further distribution of this work must maintain attribution to the author(s) and the title of the work, journal citation and DOI. Published under license by Materials Research Forum LLC. 
X-ray diffraction is the most accurate and best developed method of quantifying mainly the surface residual stress for weld repair analysis, but for X-ray diffraction the penetration depth and resolution is of lower magnitude and surface residual stress is generally misleading on the weld bead region due to surface deformed layer in the material. In order to determine residual stress, the strain in the crystal lattice must be measured with reference to a precisely known reference orientation from a sample surface. X-ray can also be used for sub-surface measurement by removing material (incremental etching) making it a semi-destructive technique [4].

As a result, it is normally recommended that surface and subsurface stresses are measured to fully understand and characterize the residual stress fields that are developed. Surface residual stress measurement is quite straight forward, but for the subsurface residual stress X-ray diffraction becomes a semi-destructive technique. X-ray has the tendency to be absorbed when passed through a material, so naturally that will affect the intensity, and in-turn the intensity affects the penetration depth, so material needs to be removed to measure residual stress at sub-surface level $[5,6]$.
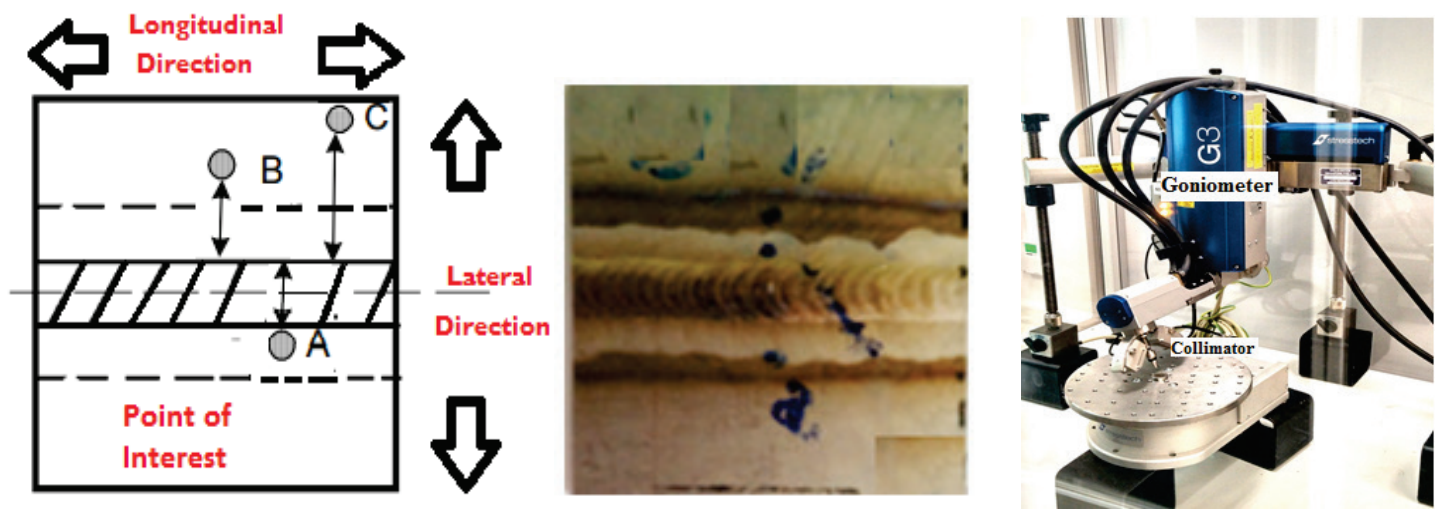

Figure 1. (a)Point of interest on welded specimen,(b) Ti-6Al-4V Coupon (c)Experimental setup for residual stress measurements.

Xstress 3000 is the equipment shown in Fig. 1(c) used for residual stress analysis, this equipment is specifically used for stress measurement on simple and complex geometries. The equipment is required to be calibrated with stress-free samples and known residual stress specimens before measurements on the specimens (Table 1) [7].

The test coupons shown in Fig. 1(b) are made up of Ti-6Al-4V, the machined specimen shown in Fig. 1(a) is a flat plate of $50 \mathrm{~mm}$ x $50 \mathrm{~mm}$ x $3.42 \mathrm{~mm}$ dimensions. Two specimens of diffrent thicknesses are seperatly flat-bead welded with similar Tungeston Inert Gas welding specifications for residual stress analysis (Table 2). Figure 1(a) indicates the points of interest where the residual stress is required to be analyzed at surface level. Point measurement was carried on the weld-bead, $\mathrm{HAZ}$ and base-metal region, with a $3 \mathrm{~mm}$ collimator, which helps to focus the X-ray for accurate measurement. Residual stress is measured in both lateral and longitudinal direction, generally the peak stress concentration area is in longitudinal direction along the weld-bead and heat affected zone.

a)

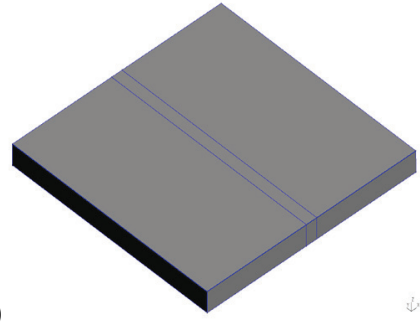

b)

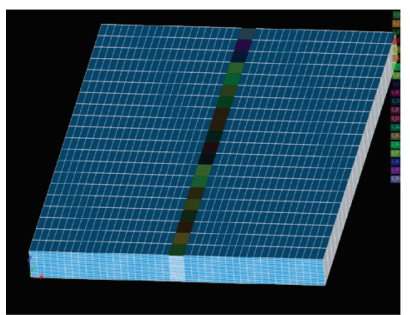

Figure 2. (a) CAD and (b) finite element model of the flat specimen. 
Table 1: Xstress 3000 experimental measurements

\begin{tabular}{|rll|}
\hline$\{\mathrm{hkl}\}$ & - & $\{213\}$ (used for copper tube) \\
\hline Psi angles/Tilt oscillation & - & $0,-25.8,-38.0,0,25.8,38.0 / \pm \mathbf{3}$ \\
\hline Exposure time & - & $70 \mathrm{sec}$ \\
\hline Measuring Mode & - & Modified $\chi$ \\
\hline X-ray Voltage & - & $30 \mathrm{kv}$ \\
\hline X-ray current & - & $10 \mathrm{~mA}$ \\
\hline Collimator distance & - & $12.7 \mathrm{~mm}$ \\
\hline Post processing-Calculation & & \\
Background & - & Parabolic \\
Fit & - & Gauss fit \\
\hline
\end{tabular}

\section{Modeling}

The finite element model of the specimen has been developed for simulations (Fig. 2). The CAD of the plate (Fig. 2(a)) has been created using the geometry module of Salome [9]. The plate volume has been partitioned into three parts by two section planes to highlight the volume under the welding zone. Simple hexagonal mesh has been created using uniform wire discretization method with $\mathrm{N}=15$ in the mesh module of Salome. The welding area width is set to $3 \mathrm{~mm}$, and the welding area mesh faces are sorted into 20 groups along the welding direction. To simulate the welding process, the moving heat source method is applied to the welding area faces (colored in Fig. 2). Since the total welding time is estimated to be around 20 seconds, each highlighted mesh group receives a heat flux pulse for the duration of 1 second consecutively. As the welding process moves in the lateral direction, the $i$-th mesh group receives a heat flux boundary condition between the (i-1)-th and $i$-th second. Additionally, a more advanced method called here "moving heat source with a trace" is applied here for comparison. This method leaves the residual heat flux as a boundary condition for the $i$-th face after the $i$-th second, exponentially decaying with time. The purpose of the method is to simulate the filler metal deposition on the base plate, which continues to transfer the heat to the specimen after the welding head has moved away from the point. The thermal and structural solutions of the model are generated using the Code-Aster software package and post-processed in Salome [10].

\section{Results and Discussion}

Initially X-ray diffraction is set to the required specifications, and calibration is carried out with stress free and known stress samples. Then followed by some preliminary analysis on magnitude of residual stress based on specimens with different thicknesses.

\begin{tabular}{|c|c|c|c|}
\hline \multirow{2}{*}{$\begin{array}{c}\text { Residual stress is measured on either } \\
\text { sides of weld-bead in the HAZ of } \\
\text { specimens }\end{array}$} & $\begin{array}{c}\text { Thickness of Ti6/4 Welded } \\
\text { Specimens (50mmx50mm) }\end{array}$ & $\begin{array}{c}\text { Longitudinal } \\
\text { direction }\end{array}$ & $\begin{array}{c}\text { Lateral } \\
\text { direction }\end{array}$ \\
\cline { 2 - 4 } & $\mathbf{1 m m}$ & High tensile stress & Low tensile stress \\
\cline { 2 - 4 } & $\mathbf{3 . 5 m m}$ & Medium tensile stress & Low compressive stress \\
\hline
\end{tabular}

Table 2: Magnitude change in residual stress.

The specimens used for the analysis were welded in similar conditions, i.e. residual stress measured along the HAZ of specimens is tabulated, this will enable understanding the stress range due to 
varying thicknes of the specimens. The thickness of the specimen or the component has an effect on the magnitude of the residual stress due to welding (Table 2).

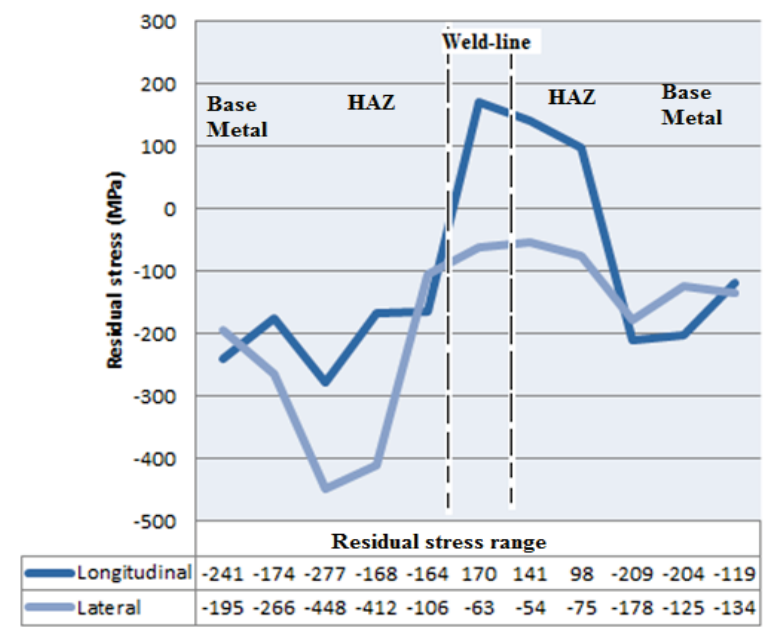

Figure 3: Surface residual stress distribution of TIG welded specimen

Residual stress is measured at different data points on the weld-bead, along HAZ and base metal region. Figure 3 shows that residual stress distribution for TIG welded specimen of $3.5 \mathrm{~mm}$ thickness. XRD equipment measures residual stress at surface level to a depth of less than 10 micron and close to 5 micron when using a copper tube. Figure 3 shows residual stress is completely distributed in the compressive stress region towards the base metal and HAZ region for both the longitudinal and lateral stress, while along the weld bead along the longitudinal direction stress is distributed in the high tensile region compared to lateral stress. Another observation is that the stress is linearly increasing (towards tensile region) along the weld-bead in both the directions. The maximum stress is around $450 \mathrm{MPa}$ compressive along the lateral direction close to the HAZ. The stress distribution is not symmetric on either sides of the weld because of minor shift in the consistancy of welding parameters, eg:welding speed, uneven weld etc.

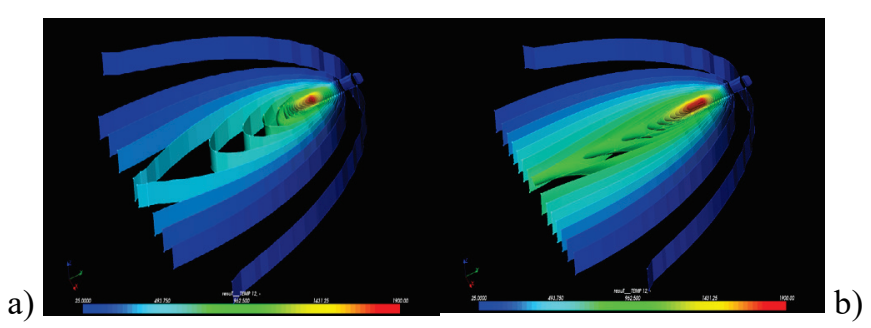

Figure 4. Isothermal surfaces on the specimen during the simulated welding process. (a) Simple moving heat source method. (b) Moving heat source with a trace.

Figure 4 shows the comparison between the simulated isothermal surfaces during the welding process using two different methods. Figure 4(b) corresponds to the thermal field solution generated from the "moving heat source with a trace" boundary conditions. The isothermal surfaces in Fig. 4(b) have higher elongation and are assumed to better match the additional thermal effects from the filler material deposition than the conventional moving heat source model solution shown in Fig. 4(a). 
a)

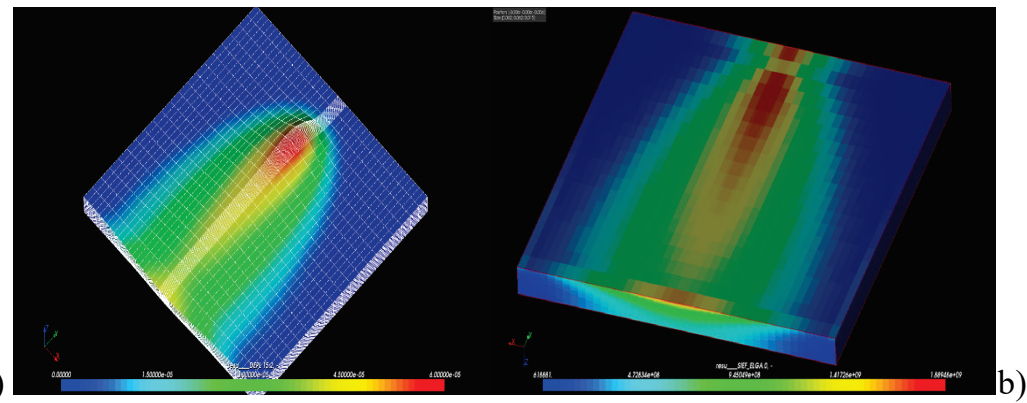

Figure 5. (a) Displacement field map with deformed surface plot and (b) thermal stress field during the simulated welding process.

Figure 5 illustrates the thermo-mechanical effects during the welding process. Local heating of the plate causes the significant displacements occur around the weld line due to the thermal expansion of the plate material. The displacements are shown in Fig. 5(a) with a scale factor of 50. In turn, displacements are linked to the thermal stresses appearing around the heated zones as result of the elastic response (see Fig. 5(b)).
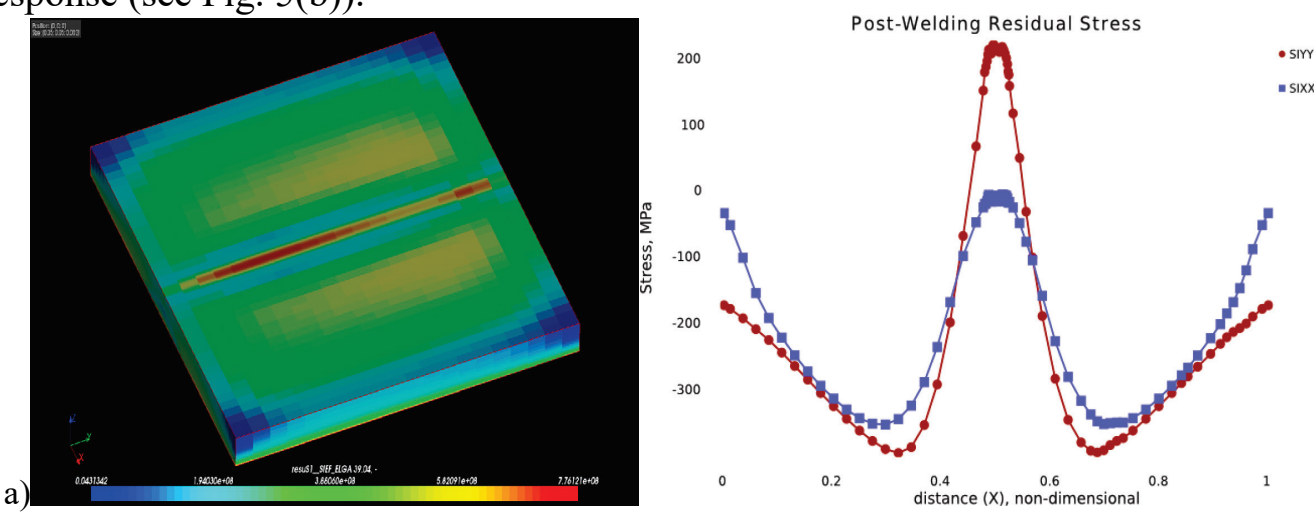

b)

Figure 6. (a) Post-welding von Mises residual stress field. (b) Plots of the longitudinal (SIYY) and lateral (SIXX) principal stress components of the residual stress tensor. The plot uses data points along the line perpendicular to the weld line.

Finally, the simulated welding process reaches the edge of the plate after $20 \mathrm{~s}$, and the plate starts to cool naturally. Then, after another $20 \mathrm{~s}$ period of heat dissipation and natural convection, the thermal gradients inside the plate smoothen out, and the residual strains and stresses caused by elasto-plastic effects show up. Figure 6(a) shows the von Mises stress field plot after $20 \mathrm{~s}$ of welding and $20 s$ of natural convective cooling. Peak values are concentrated along the thin weld line zone. The last diagram shown in Fig. 6(b) illustrates the dependency of the stress components on the position in the lateral direction. Longitudinal stress reaches the peak tensile values in the vicinity of the weld line and peak compressive values in the HAZ. Lateral stress has very low absolute values near the edges and near the weld line, but reaches high compressive values in the HAZ (please refer to Fig. 6(b)).

\section{Conclusion}

It is concluded that the numerical analysis of weld residual stress appears to have a good agreement with the XRD measurement. The agreement was based on the stress graph from experimental and numerical analysis, and the range of the stress values in the three regions of the weld specimen are matched as a part of the preliminary validation study. The stresses measured in both longitudinal and transverse direction seems to have a fair correlation with modelling, considering the diffrence in experimental measurements due to the minor shift in welding consistency of the specimens; peak 
tensile stress is observed along the weld-bead, it can be seen to decrease and shift to the compressive region between the heat affected zone (HAZ) and the base metal region, peak compressive stress is observed near the HAZ along the longitudinal direction for both modelling and experimental measurements. Thus the comparison between measured stress profiles and model predictions at the surface level has been established with good agreement.

Future studies will mainly focus on a flat plate with minor amounts of material removal and comparing them with specimen thickness for sub-surface residual stress measurements by X-ray diffraction, and the respective correlation to sub-surface measurements by stress modelling.

\section{Acknowledgements}

This work was conducted within the Rolls-Royce@NTU Corporate Lab with support from the National Research Foundation (NRF) Singapore under the Corp Lab@University scheme.

\section{References}

[1] Warren, A. W., \& Guo, Y. B. Characteristics of residual stress profiles in hard turned vs. Ground surfaces with and without a white layer. ASME. J.Manuf. Sci. Eng. (2009), 131 (4). http://dx.doi.org/10.1115/1.3159046

[2] IDC Technologies. Residual stress in welded joints. IDC technical references Lecture 21. (2003) U.S.A.

[3] Cammet, J. Quality assurance of shot peening by automated surface and subsurface residual stress measurement. Lambda Research-The Shot Peener, (2001) 15(3), 7-8, U.S.A.

[4] Fitzpatrick, M. E., Fry, A. T., Holdway, P., Kandil, F.A., Shackleton, J., \& Suominen, L. Determination of Residual stresses by X-ray diffraction. National Physical Laboratory-Measurement Good Practice Guide No. 52. (2005), U.K.

[5] Suzuki, T. Masaaki, S. Hatsuhiko, O.T.N. Muneyuki, I.Y.T. Hiroshi, S. \& Atsushi, M. Residual Stress Measurement of Welding Area by Neutron Diffraction Method. Nippon Steel Technical Report 100, (2011), Japan.

[6] Kumar, S., Tan, M.J, Wong, B.S, \& Weeks, N. Post Weld Heat Treatment surface residual stress measurements using X-ray diffraction, Emerging Technologies in Non-Destructive Testing VI-CRC Press. Dec. (2015), 563 -567, Belgium. http://dx.doi.org/10.1201/b19381-93

[7] Stresstech Group, V1.5, . Xtronic Guide -Stresstech Guide, Finland, (2013).

[8] Modenesi, P.J. Apolinario, E.R. \& Pereira, I.M. TIG welding with single-component fluxes. Journal of Materials Processing Technology,(2000), 99(1), 260-265. http://dx.doi.org/10.1016/S0924-0136(99)00435-5

[9] Salome, open source platform for CAE problems: www.salome-platform.org/, (2016).

[10] Code_Aster, open source - general FEA software: www.code-aster.org/, (2016). 